\title{
Violence as a language of construction and deconstruction in Rio de Janeiro and Brazil
}

\author{
Luiz Eduardo Soares
}

\section{Preface by Michael Keith}

The following chapter is written by Luiz Eduardo Soares, an academic notable for a professional biography that has moved back and forth between the ivory tower and city government. Soares has served as Professor of Anthropology at the State University of Rio de Janeiro and was the National Secretary of Public Security under the mandate of Lula's presidency in Brazil.

Soares's chapter starts with the appalling statistic that between 1980 and 2010 over one million Brazilians were murdered. It is in the face of such data that violence is increasingly defined as a public health crisis in several parts of the world similarly scarred, as well as in Brazil itself. More pointedly, Soares suggests that if we are not careful such data is dehumanised. He appeals to the need to put a face to the figures. And the faces are clearly identified by the history of the city and the racialisation of the country. The faces of those who have died are massively disproportionately concentrated on one fraction of the demos of Brazil and configuration of its urban geography. As he puts it in the chapter, the victims of murder have 'a colour, a class and an address'. And in making the victims visible, in humanising the data, he argues that Rio de Janeiro can be seen as a microcosm of the country at large.

Soares has described his own paradoxical love-hate relationship with the city in the extraordinary book Rio de Janeiro: Extreme city (2016). The book is part autobiography of his own attempts to challenge the pandemic of violent death, and part an interdisciplinary mixture of a sociology of the city's favelas, an anthropology of the regimes of metropolitan governance and a political science of the institutional architecture of 
the Brazilian state. It describes in self-effacing and vivid detail his own attempts to engage, mediate, mitigate and even at times address and solve the complex system of everyday complicities between the state, its institutions and the agents of violence on both sides of the law. $\mathrm{He}$ describes movingly the times in which the logic of a poorly designed state architecture and the deep histories of exclusion, polarisation and racism have led to a rationally logical complicity between municipal corruption and gang violence in the favelas; how the arbitrary violence of 'pacification' of favelas masked an entrenchment rather than a solution to the powers of informally governed parts of the city where those with guns ruled. It is a story that contains both surreal humour and understated bravery.

In Extreme city Soares narrates how his lifetime of political engagement dating back to the fights against the military dictatorship in Brazil (1964-85) informed his links to Lula's Partido dos Trabalhadores (PT, or Workers' Party) and led him to the years of qualified optimism of urban reform in Rio. Lula's personal base always favoured São Paulo (and his football team Corinthians) over Rio, but his controversial presidency demonstrably attempted to address the scale of inequality in the country and the plight of the poorest nationally. Lula's rule overlapped with what the Financial Times and some economists have come to call the 'NICE' decade from 1998 to 2008 . The decade was characterised by global economic growth and liberalisation of world trade with Non-Inflationary Continuous Expansion' the marker of most of the largest economies in the world. It also coincided with the award of the 2014 World Cup final and 2016 Olympic Games at a time when Brazil stood as one of the 'BRICS' (the B alongside Russia, India, China and South Africa). For the former Goldman Sachs guru Jim O'Neill, the BRICS were the 'rising powers' that would drive the world's economy in the twenty-first century.

So it was against this backdrop of global growth and national optimism that Soares's engagement with the governmentalities of Rio was set. His contribution to this volume links directly to Chapter 3, by McIlwaine et al., which is set in part in Maré, one of the larger favelas in Rio. In Extreme city, Soares describes the regimes in which the favela has for many years been under the 'drug lord control' of three factions that have operated across Rio but have divided Maré territorially between them.

Soares argued at the time for what many considered unthinkable: some kind of qualified pardoning of drug lords, linked to a peace process 
that learnt from international precedents. His book describes in some detail the attempts he made to realise such a change. But in the run-up to the Olympics the pressure to demonstrate the 'rule of law' across the whole of the city led to the creation of the Rio Favela Pacification Units (the UPPs). The favelas to be pacified were not chosen randomly. As he puts it, 'UPPs were established only in a few dozen locations in the Olympic belt, in other words close to wealthy neighbourhoods' (Soares, 2016: 110). As we have seen with other cities addressing the challenges of public health, Rio is driven by struggles for the future of the city shaped by its traumatic and problematic past. It is in this sense that Soares writes here against the grain of history to consider how the scars of slavery and racism underscore so many of the challenges of the contemporary moment.

For Soares the scale of violence in contemporary Brazil can be understood only through a prism of political philosophy, anthropological enquiry and forensic sociological examination of the data. It needs to be mapped against the historical legacies of the formation of the Brazilian nation state and the fusion of a Brazilian 'society' amid the legacies of treatment of indigenous peoples, the political economy of slavery and the urban realisations of colonial settlement. Soares consequently in his chapter in this volume attempts to link the philosophy of Georg Wilhelm Friedrich Hegel, the anthropology of Eduardo Viveiros de Castro and the concentrated geographies of violence to make sense of the public health pandemic that he tried to address in his time in public office in the 'extreme city' of Rio de Janeiro.

In 1807 Hegel wrote his canonical text The phenomenology of spirit, in which he invoked a dialectic of modernity structured by the tensions between independent and dependent self-consciousness, parsed through the relationship between master and slave. In later writing and in the Hegelian legacy in philosophy the struggle for the freedoms of self-consciousness have been cast as the master-slave dialectic. It is this dialectical relationship that forms a central theme in Soares's chapter.

Taken out of context and out of time, this becomes in Hegel's prose at worst an offensive indictment of slave consciousness, prefiguring nineteenth-century explanations of cultures of racialised poverty. So for Hegel famously if a man is a slave, his own will is responsible for his slavery, just as it is its will, which is responsible if a people is subjugated. Hence the wrong of slavery lies at the door, not simply of enslavers or conquerors, but of the slaves and the conquered themselves' 
(Hegel, 1991, art. 57). For Susan Buck Morss (2009) Hegel has to be read historically as an author writing in the shadow of the slave rebellion that won independence for Haiti in 1804. The Haitian Revolution had exposed the border limits and hypocrisies of the French Revolution's appeal to a universal human subject. As the Caribbean scholar C.L.R. James tellingly argued in his 1938 work, Black Jacobins could make a claim in the name of liberté, égalité and fraternité, but slavery was to remain central to the political economy of post-revolutionary France.

More powerfully still, Paul Gilroy (1993) in his landmark postcolonial work The Black Atlantic argues powerfully that Hegel's master-slave dialectic should be inverted. Euro-American modernity, for Gilroy, should be viewed through lenses of the gendered subjectivities of the slave, deconstructing the myths of rational Enlightenment and its appeals to universality and progress and unpacking the colonial complicities that in part shaped contemporary liberal democracy.

In the city, just as wealth is distributed unevenly across society, so too is violence distributed unevenly across geography. These asymmetries map onto the old divisions of demos: divisions that challenge the definition of a singular 'society', pluralise a sense of publics and complicate a notion of public health in Brazil. For Soares the great migration in Brazil that increased the urban population from 37 per cent in 1950 to 86 per cent in 2010 reproduced these historical divisions in the DNA of the city. The attempt to dwell in the metropolis for those who moved, to make a home in an urban environment that was less than homely, was structured by historical racism and contemporary injustices. The chapter looks through the lens of the longue durée which shapes the urban form as pathogenic, the public health propensities of violence shaped by the infrastructures of twentieth-century urbanisation. Consequently, the register of voice in this chapter is very different from the discussions of public health in the rest of the volume. But the editors believe that the insights of the chapter inform and are in turn informed by an anthropological imagination that confronted the very real public health challenges of mass violence in Rio de Janeiro in recent years and provide powerful insights into the depth of deep-rooted divisions in the Brazilian city.

The end of his engagement with running national security and Rio policing was not a happy one for Soares, yet nowhere might we see better the power of the Gramscian injunction for an optimism of the soul, a pessimism of the intellect. It prompts Soares and others not to give up, perhaps matching Gramsci with Beckett's appeal to 'fail again, fail 
better'. It is also against the background of this biographical engagement that this chapter should be read.

\section{Introduction}

Max Weber said that the role of sociology is to exaggerate. By exaggerating, it highlights phenomena and focuses on the object. This means it is not unreasonable to draw the analogy that the city of Rio de Janeiro is a sociological version of Brazil. In other words, Carioca society, which lives in a range of different neighbourhoods and favelas, is a clear and dramatic reflection of Brazilian society itself. There are six billionaires in the country with a combined income equivalent to that earned by 50 per cent of the population - the equivalent of 105 million people; in the city of Rio, one can cross the street and go straight from areas with twenty-first-century European standards of living into some of the poorest areas in Brazil.

In the more affluent neighbourhoods of Rio de Janeiro's Zona Sul such as Copacabana and Lagoa, a significant proportion of the population (41 per cent and 48 per cent respectively) have a monthly income more than five times the minimum monthly wage. In favelas like Rocinha, Jacarezinho and Cidade de Deus, only 1 per cent achieve this; and in other poorer neighbourhoods like Pavuna and Santa Cruz, only 2 per cent achieve the same income (IBGE, 2010).

One of the characteristics of Brazilian society, which in Rio is paradigmatic, is the increasingly common lethal violence that has been 'naturalised' by the middle classes and the elite. The focus here is on murder. This is considered the most serious crime, and is one that leaves no doubt of its heinous violence. The historical data available goes back only to 1980 ; however, this data shows that such lethal violence is not 'democratically' distributed. Rather, there is a significant concentration on the process of victimisation.

\section{The victims have a colour, a class and an address}

Over the thirty years from 1980 to $2010,1,098,675$ Brazilians were the victims of murder. The figures jumped from 11.69 murders per 100,000 inhabitants in 1980 to 29.7 for the same number in 2016. In real terms, the numbers of people murdered annually increased from 13,910 to 61,158 over the whole period. 
If one looks at the data for 2009, the year in which Professor Julio Jacobo Waiselfisz conducted his detailed survey, the Mapa da violência (Map of violence), published by the Ministry of Justice in 2011, one sees that 90 per cent of murder victims were male, 54 per cent were aged between nineteen and twenty-nine years, 75 per cent were killed by firearms, and 65 per cent were black. The risk of a young black male being killed is 2.96 times greater than that of a young white male. This was not an atypical year, so one can make out a pattern of deadly violence in the country that tends to affect poor disadvantaged young males, particularly black males, and that these crimes are mostly committed with guns 76 per cent in Rio de Janeiro. It should be pointed out that this data is an accurate reflection of that for the state and city of Rio de Janeiro itself.

In 2010 the number of young people aged between eighteen and twenty-four who were in neither education nor employment in Rio was 186,133 , or 26.8 per cent of the total. The highest incidences of 'neither-nor' young people were in disadvantaged neighbourhoods like Jacarezinho (38.8 per cent), Bangu (35.1 per cent) and Santa Cruz (38.4 per cent) (IBGE, 2010).

Between 2005 and 2014 there were 18,243 murders in Rio de Janeiro. The variation is more meaningful than the quantity: in 2014 murder rates per hundred thousand inhabitants in the city's most well-to-do area, the Zona Sul, ranged between 3.6 and 3.9, while in the Zona Oeste it was 34.6 and in the Zona Norte between 30.8 and 33.9. In addition, the three Integrated Public Safety Areas (AISPs) with the highest incidence of deaths resulting from police raids - AISP 41 and AISP 09 in the Zona Norte, and AISP 14 in the Zona Oeste - accounted for 55.5 per cent of all occurrences recorded between 2012 and 2015.

This transversal solidarity that can unite the whole city, the whole country, is rarely manifest, and appears only in the throes of indignation and cries for justice and vengeance. In general, it is reactive and negative, as fear reinforces prejudice and contributes to the intensification of inequality. In any acute crisis situation, it is natural to lean towards punitive measures. At times such as these, demagogic leaders tend to ride the tide of passion and try to connect the energy that is created with a rhetoric of greater punishment. After rebellion, the catastrophic policing and prison routines return. Nothing changes. The legal system continues to be intransigent, and the government returns to its traditional stances, with few exceptions. The Justice Department does not contemplate any change. 
This gloomy scenario is not limited to the volume of murders. It also extends to the ineffectiveness of policing and investigation. According to the survey Mapa da violência, on average only 8 per cent of murders are actually investigated (Waisselfisz, 2011).

On the basis of this alarming information, many people assume that Brazil is a country of impunity. However, they could not be more mistaken. Brazil has the fourth largest prison population in the world. In 2013 there were already over 550,000 prisoners, whereas in the mid1990s there were only 150,000. In 2017, although the figures have yet to be confirmed, there were a staggering 700,000 prison inmates. This increase is shocking, and its speed of growth deeply concerning.

\section{Prisoner hunger}

Of these prisoners, approximately 12,000 have been incarcerated for lethal crimes, 40 per cent of whom have yet to be formally sentenced or even gone to trial. Almost a third (28 per cent) of the prison population are serving sentences for drug dealing. It is clear that incarceration for life-threatening crime and gun use is not a priority. The focus is on drug possession and drug dealing.

In Brazil, drug dealers are expected to serve a minimum sentence of at least four years in a closed prison system, which almost completely eliminates the opportunity of any alternative penalty. Even if those who have been convicted have not been involved with gang activity, or have not committed violent crimes, they are still likely to lose their freedom. The cost to the taxpayer for each inmate is 1,500 Brazilian reales every month: a sum that could be used far more productively to transform the lives of those in prison, to promote their reintegration into society via education, employment opportunities and effective support for their families, and to offer both them and society more positive outcomes. In accordance with current legislation set by Decree 11.343/2006, drug users cannot be arrested, but should instead be taken to the local police station and then a Special Criminal Court, where they receive a verbal warning and are required to do a period of community service or a measure of compulsory attendance for an educational programme or pay a fine. Consumption of illegal drugs though continues to be considered a crime.

Brazilian law does not make a clear distinction between possession and dealing of drugs, and this further blurs interpretation by the courts 
and, indeed, by the police. With such blurred boundaries at their discretion, the majority of magistrates inevitably reproduce social inequalities. Their subjective assessments, which have very objective effects, tend to reiterate the discrimination of the culture in which they were brought up - one that continues to prejudice social inequality. The effects of this cocktail have been far more serious than the ingestion of any drug.

The result is the following: if the suspect is a young, white, middle-class male from a relatively affluent neighbourhood, he can defend himself with clever words: 'I'm addicted, your honour, I admit I'm a slave to addiction. But I hate having to contact dealers, I hate having to meet up with those kinds of people. I don't want to be involved with crime. That's why I buy the most I can at any one time so I don't need to meet up with them too often.' The judge usually feels sorry for the poor lad, shows clemency and doles out the treatment that he supposedly needs and deserves. In the eyes of the law, there is no doubt: he is a user. It will rarely occur to a similarly aged suspect who is black and poor and lives in a favela to defend themselves so cleverly. They could then run the risk of being sent down with the maximum sentence for disrespecting authority, and their explanations ridiculed. In the eyes of the law, this young man is a drug dealer. The middle-class white boy is seen as an 'addict', to be treated with paternalistic indulgence, while the disadvantaged black youth will be locked up for at least four years and given training for his return to freedom. Even though he may not have been violent or armed, even if he acted alone simply to make some money, he will now learn to organise himself, arm himself and use violence to achieve more ambitious aims. In Brazilian prisons, nobody survives without being affiliated to a gang.

In addition, the unfairness of the system grinds down self-esteem, and is humiliating, depressing and degrading. Prospects for escaping the cycle are minimal. This pessimistic prophecy for young offenders is almost always fulfilled, and thereby confirms prejudice, not because it is correct, but because the mediation of criminal policy transforms prediction into fact.

\section{Police models, drug laws and the criminalisation of poverty}

The steep increase in Brazil's prison population since 2003, its marked social profile and racial background, and the perverse choice of crimes that are particularly targeted are due to social and economic issues, and 
profound inequality and structural racism. However, although this is frequently forgotten, they are also due to the inheritance of an institutional and organisational public security structure left over from the days of the dictatorship - particularly in the way the police are organised, dividing work cycles between themselves, and in their openly militarised nature. This situation is also due to the security policies used, and it would not be possible if the disastrous approach to drug laws were not so prevalent. One should note that this institutional architecture is part of the broader field of criminal justice, and that this, in turn, means that police functioning, structured in terms dictated by a constitutionally defined model, produces dual results both with crime policies and with the connection between the civil police (non-uniformed), the Public Prosecution Office, the courts and the prison system. There is a systemic perversion of justice, with every agency sharing responsibility and being complicit in the barbarism: the prison environment is nightmarish and inhumane, and not even the state meets its own legal obligations. This brutality spills out on the streets and reconnects with its beginnings, generating and strengthening the increasingly powerful and influential criminal gangs throughout the country.

The way a group is organised is, to a greater or lesser extent, always influential in shaping the behaviour of its members: this is particularly true of institutions where discretion and arbitrary decision making are distinguished by complex, dynamic criteria and instability. In Brazil this correlation is extreme. One example is the military police, owing particularly to the nature of their duties. According to article 144 of the Federal Constitution, the military police are responsible for the public, carrying out a form of uniformed policing that is also known as preventive. Given the division of labour dictated by the same article, which assigns investigation exclusively to the civil police, the military police are responsible for undertaking arrests 'proactively', and for seizing drugs and weapons. The arrests of what kind of perpetrator, though? Acting against what kind of offence? If their duty is to get things done, and if getting things done is synonymous with making arrests yet they are not allowed to investigate, how can this problem be solved? By arresting people in flagrante. To what kinds of crime does this apply? There are several, but they do not include money laundering or many of the other transgressions perpetrated by white-collar criminals. The kind of people who occupy the military police prisons are almost always from the streets: pickpockets, small-time drug dealers, petty shoplifters, car 
thieves and so on. In general, who are the people who commit these kinds of offences? Often, they are poorly educated and disadvantaged young people from the poorer neighbourhoods and favelas, whose constant trials have led them to seek alternative routes to economic survival. The trick that makes military police action appear so 'effective' - when assessed according to rates of incarceration rather than the results that should be the priority (i.e. reducing violence) - is to make catching criminals only in flagrante on a widespread scale a legal tool: the criminal policy on drugs and the prohibitionist legislation from which it derives. This has created a mechanism whose smooth functioning has overcrowded prisons with young people who were unarmed when arrested, were not gang members and had not committed violent crimes. The name of this process is the criminalisation of poverty, and it is the stamp of institutionalised racism. This approach to criminal prosecution, used exclusively by the police, requires the law to be applied in a highly irregular fashion; therefore recourse to the drugs law should also fall under the remit of the basic constitutional principle of equality, class and race. It is this approach that makes access to true justice one of the most disheartening and dispiriting elements of Brazilian society. It should also be noted that the state does not meet the requirements of the criminal punishment law, and this suggests that criminals are subjected to longer incarceration than the sentences they should in fact have received. This process is particularly marked in Rio de Janeiro.

According to a survey by Luciana Boiteux (Boiteux et al., 2009), 80 per cent of those arrested for drug dealing were young people aged between sixteen and twenty-eight. Most were caught in flagrante, were not armed, had not committed a violent act and had no ties to criminal organisations.

\section{State violence}

There is a further element that has increased the levels of violence and requalified them. This refers, in particular, to Rio de Janeiro state between 2003 and 2016. Over this period, 12,263 people were killed through police action. The police fulfil orders and apply the lessons they learnt in training. The organisational culture has not undergone any significant revision since the dictatorship (the first fully democratic constitution was only promulgated in 1988, thus formally ending a long political transition). The enduring belief that the police are fighting a war 
prevails, and this means that any response is permissible. These military values define suspects as enemies to be eliminated, and define the population that lives in 'target' neighbourhoods as potential accomplices. The frequent deaths of innocent residents within poorer communities tend to be justified as accidents or as a means to an end. It is important to add that almost all the victims of extra-judicial execution are poor, young, frequently black, males from the favelas and poorer neighbourhoods.

With the development of twenty-first-century capitalism in Brazil, and perhaps because of its traditionally authoritarian background, there is a resistance to conventional social fomations, interpreted as distortions of category, experience and value. This leads to a lack of ability to nurture relationships of the 'I-You' type in the collective imagination and the day-to-day social fabric, ones that correspond to a particular kind of otherness: a kind of relational template with the 'Other' that is against violence and in favour of dialogue. This does not naively assume that in a society defined by class, and particularly in one that is so dramatically unequal, sociability can be governed by dialogue and mutual respect, thereby consecrating human rights. Brazilian society, and particularly Carioca society, stands in its structure in stark contrast to that hoped for by humanists on the basis of ethical principles and fairness. This constitutive brutality exists not only between classes or between state bodies and the less privileged classes. It is also common within the individual classes.

These tragic levels of violence have become a major reference point that both unites and separates Cariocas (in this case, the interpretation applies to Brazilian society, but they are reflected in Rio de Janeiro in a particularly significant fashion), and continue to be part of society only because of the echoes from a deeper, longer and more constitutive brutality of ontological dualism promoted by slavery and reiterated by the exploitation of labour, the magnitude of inequality, the distancing of the elitist state and the authoritarian nature of the hybrid and conservative capitalist modernisation of today's Brazil. Racism provides the historical template through which class divisions are formed in Brazilian society. Violence becomes a language, the behavioural template provided by the city to its residents, and it is within this semantic definition that the metropolis is experienced and qualified. Violence overshadows relationships and becomes second nature, undermining the republic and constructing and de-constructing identities and images of citizenship. 


\section{Historical genesis: path dependencies of slavery shaping emergent futures}

The master-slave relationship is not just a few (or more) degrees more intense than any other kind of work exploitation; rather, it represents different points along a single line, or gradations along a continuum. The master-slave relationship is the ontological reduction of human beings to productive tools and commercial objects. This brutal and deconstitutive movement by the Other is unparalleled, even in the capitalist reification of workers, who are obliged to sell their labour: the two are entirely distinct processes. While from the human rights perspective people are unique and incomparable, irreducible to any equivalences and resistant to manipulation, slaves are de-personalised, de-individualised, dehumanised and reduced to a monetary series of equivalencies. The economic-political-moral-cultural operation that enslaves a human being for regular use and abuse, not only through force but also through applying an institutionalised set of standards, is a social fact, a monstrous event that introduces a second nature and creates a chasm between two ontologies.

Eduardo Viveiros de Castro's inspiring lucidity is apt here; his theory of Amerindian perspectivism inflects how we consider the dilemmas of freedom and self-consciousness and offers some enlightening analogies:

My task was to identify elements in various indigenous cultures that would allow me to build a model that is - in a certain sense - ideal, in which the contrast with the naturalism characteristic of European modernity became more evident. ... The proposition in their myths is that animals were humans but ceased to be so, and that humanity is the shared root of both humanity and animality. In our mythology, it is the opposite: we as humans were once animals, but 'ceased' to be them with the emergence of culture, etc. For us, the generic shared condition is animality: 'the whole world' is animal, but some are more animal than others, and we are the least animalistic. In indigenous mythologies, the whole world is human, only some are less human than others. There are several animals that are very distant from human beings, but they are all, or almost all, human in origin, and this goes against the idea of animism, which is that the universal foundation of reality is the spirit. (Viveiros de Castro, 2008: 480) ${ }^{1}$

The myth for the origins of Brazilian society tells the story of three races that formed a fellowship, combining their strengths to form the 
Brazilian nation: native Indians, Africans and white Europeans. The European colonisation of Brazil tells a different story, in which the native Indians and the Africans were taken advantage of to build the power and wealth of the white Europeans, themselves divided between the exploited and the exploiters. What is important to focus on here is the introduction of a different symbolic constellation, the roots of which were sown deep in the experiences of individuals and which marked all social relationships. The slaves were not humans who had been animalised in order to become goods and tools of labour; neither were they animals that had reached a subhuman intermediary stage to serve their masters, with the hope of perhaps one day achieving full human status. Slavery instils a third ontological order, for which both descriptions are inappropriate. This ontological displacement is in the perspective of the masters, the law and the institutions, and is manifested in the field of social practices. Slavery is exile from humanity. Resistance does not come only through direct confrontation. It also comes from the silent insistence of knowing oneself to be human, and from asserting one's sense of dignity despite the white exploiters' attempts to destroy this. Even if they do succumb to their master's humiliating orders, slaves cannot be criticised or judged, as they are merely accepting what liberal countries called the 'natural law' in order to survive (Pinsky, 2010). This means that slavery did not actually degrade slaves' humanity, as they were the victims. Rather, it degraded that of the masters and exposed their moral turpitude from the perspective of those whom they exploited: the slaves. However, from the perspective of the masters, the slaves were nothing more than goods. Two dehumanities lived alongside each other but could not relate - one produced by the violence of slavery and the commercialisation of human beings, and the other produced for the benefit of the masters, their sidekicks and those who stood to benefit from the system. Slavery is not a relationship. The two ways of being show an ontological duplicity.

\section{The hypothesis of a dual ontology}

There is no communication between the two ontologies: slaves do not suddenly become human to their masters when they are caressed, or when their human attributes - sexual and emotional - are recognised. They may be treated with kindness, but they continue to be slaves, remaining within the inhuman order to which they belong - inhuman from the point of view of practice, abiding laws, the economy that needs 
them and the exercise of power. There is no oscillation between being and not being a slave according to a master's moods and desires or depending on the communicative register or the way the patriarch chooses to treat his slaves. The erotic idyll of a loving partner cannot be such for a libidinous master, as because she is a slave, the woman is dehumanised; she cannot ever be the equal of the master. She is only an object, no matter how she temporarily experiences the transference of herself to a second body that corresponds to the human soul. In this case, the double of the slave woman exists only as that seen by the master, even though his lover may occasionally play the game and confirm the reality of the meeting and become displaced emotionally and notionally. It is a vicarious topology - one that is subject to the master's emotions, and it does not imply any recognition of the human nature of the Other, the woman who is desired. The real woman under the guise of a slave is a real human being, a subject, and is somewhere else, beyond the master's reach, his power, his values and his logic. The second body of the slave is reduced to a fantasy phallocentric projection and the extension of patriarchal authority, even though the woman who is coveted may provisionally identify with this second body and inhabit it in a similar way to a visitor to a theme park. From the most extreme slavocratic hypothesis - and from the perspective of the organisation of social power, morality and the ontological reduction of otherness - there is no difference between using the Other for pleasure or suffering if the choice comes from one's own desire, and the Other has no choice but to fulfil their designated role. This means that there is no difference if the Other is excluded from the inter-subjective dynamics in which they would hold the role of the subject - and it is this that is so important in any recognition of their humanity.

A slave cannot be a 'you' for an 'I' master in an idealised dialogue, because their position is reified as that of a third party. Direct communication flows through the rules of a machine-like, consequential and non-dialogical pragmatism: orders are transmitted and their targets are receptors; it is inappropriate to speak unless it is in order to clarify the order received - which is part of the expectations. This form of communication differs from that practised in hierarchically organised institutions, as in these it is the positions and not the individuals that make speech function as orders. In an institutional context, positions are held by individuals whose authority is reversible and conditioned. Contrastingly, the word 'slave' is the name of a position that is then 
transformed into a quality of 'person' without anything else. The designation of 'slave' strips away humanity because the word itself (and of the institution that represents it) promotes simplification, reducing it to its representation in the logic of power. If the name mirrors the thing, it is because pragmatically it constitutes it by creating a result through the act of speaking. This result neutralises potential virtues, indeed, it neutralises itself, because in this case destiny does not involve unpredictability or a random game of chance. The definition of a slave defines a being and remains frozen in time. Slaves can be bought and sold, taken from one town to another, from one workplace to another, can provide sexual services to their masters - but they cannot be what they are not. While they are alive, they will always be slaves. In this sense, they have no past or future, and not even their children are their own.

What really happens when the veto on inter-subjectivity is imposed and thus cancels out any possibility of dialogue? One answer can be found in Eduardo Viveiros de Castro's interpretation of another impossible dialogue:

Following the analogy with the pronominal series (Benveniste 1966a, b), one can see that, between the reflective self of culture (the generator of the concept of the soul or spirit) and the impersonal it of nature (a marker of the relation to otherness), there is a discursive position of the you, the second person; of the other considered as another subject, whose point of view serves as a latent echo of the $I$.

I believe that this concept can help one to determine the supernatural context. It is an abnormal context in which the subject is seen from another dominant cosmological point of view, where it is seen as the you from a non-human perspective; the supernatural is the form of the Other as the Subject, implying the objectification of the human 'I' as a you for this Other.

The typical supernatural situation of the Amerindian world is the encounter in the forest between a human being - always alone - and a being that, seen primarily as a mere animal or person, reveals itself as a spirit or a ghost, and speaks with the man.... These meetings are often lethal for the interlocutor, who, subjugated by his non-human subjectivity, passes to the other side, becoming transformed into a being of the same species as the locutor: whether dead, spirit or animal. Those who respond to a you spoken by a non-human accept the condition of being their 'second person', and thereby accepting the position that $I$ will have as a non-human.... Thus, the canonical form of these supernatural encounters consists in the sudden insight that the other is human, that he 
is human, and this automatically dehumanises and alienates the interlocutor, transforming them into prey - into an animal. This is the true significance of the Amerindian disquiet about what lurks beneath appearances. Appearances can be deceptive, as one can never be sure about what is the dominant point of view, or rather, of which world is interacting with the Other. Everything is dangerous; especially when everything is human, and perhaps, we are not. (Viveiros de Castro, 2008: 396-97; author's italics) ${ }^{2}$

This is a long quotation, but it sheds such light on the question that I feel readers will forgive me. By applying this analysis to the slavocratic cosmos at the points where the analogy seems relevant, and returning to the initial argument, one can conclude the following: if the master personalises the slave, and the latter, recognising their own humanity (recognising themselves as the human), takes part in this dialogical game and accepts the place of 'secondary person' to the master, they will lose their humanity and their autonomy, because they have allowed the master's point of view to prevail and have thereby validated the corresponding world, a world in which they are slaves, objects, prey, tools, property, things and beasts of burden. This makes it lethal for slaves to take a generous, compassionate and empathic approach, or to try to understand the master as anOther human being, hiding their own nature under the iniquitous arrogance of ownership. It is deadly because it subtracts from humanity, and returns it to the third nature that of slavery.

Avoiding or hiding from dialogues with the master (which in themselves are a trap because inter-subjectivity is impractical in this case), putting them off or trying to adopt evasive or confrontational strategies are all manifestations of resistance and of struggling for freedom and autonomy: they are the preservation of humanity itself. These manifestations should not be construed as an expression of hatred or resentment, as what is at stake is the threat of abducting slaves' humanity.

The lethal risk of succumbing to the master's seduction and moving into the space of the second person is unconsciously assimilated, and therein transmutes into the chronic and omnipresent suspicion that contaminates the culture for future generations and that may for some even if widely justified - eventually appear to be a kind of paranoid atavism resistant to cooperation and contract and sceptical of politics and justice. This persistent suspicion is particularly harmful and damaging as it concerns not only the Other, but also the self through the mediation of the Other: if the world in effect denies even the descendants of slaves 
their humanity because of the continued presence of racism and extreme inequality, identifying with it, belonging to it and sharing its nature may lead to the discovery of a shared inhumanity. In the words of Viveiros de Castro, quoted above, on a structurally analogous situation: 'Everything is dangerous; especially when everything is human, and perhaps, we are not.'

\section{Colour as the language of inequality and class}

I have tried to set out the reasons for rejecting any balance between antagonisms when describing the experience of slavery in Brazil. Applied to this specific historical context, ontological discontinuity contests concepts of permeability, hybridism and the juxtaposition of opposites and ambiguity. In this sense, I see Brazil as the reverse of the way in which it is usually described. Racism is not a manifestation of prejudice dislocated from the poor or less advantaged classes. It is quite the opposite: racism came first, and is manifest through its effect of dislocation. The root of the problem is the institutional lacuna in republican modernity that translates into a non-tacit prejudice against black and indigenous peoples, and into resisting any recognition (and experience) of individuality in a contemporary sense. It seems to me that Brazilian society is centred on great inequality, and that this ontological dualism normalises and polarises ordinary inequalities. It is as if the ontological duality that no longer exists is still vibrating and shining like stars that have been dead for millennia, and is still able to illuminate paths through the night. The light of these extinct stars continues to warp the refracted social perception through a game of smoke and mirrors, and we continue to be deceived by it and to reify it, forgetting its origins and emulating the characters of the platonic caveman myth.

The ontological duplicity instilled by slavery did not cease to exist with the legal end to slavery in 1888: the effects on Brazilian society remain as deep scars, or tattoos, and the effects have not disappeared with the mere passage of time. The marks do not disappear as they are gradually forgotten, because new experiences replace previous ones. Given the longlasting significance of slavery and the pain involved, forgetting, denying or underestimating its importance will only transform the tragedy into trauma. All the repressed suffering comes back but in a different place, resistant to interpretations, haunting, disturbing and disseminating feelings of fear, insecurity and hate. Rather than easing the suffering and 
memory of the horrors, the absence of wider societal recognition of what slavery meant to the native Indians and African Brazilians on a national scale actually perpetuates the pain and distances it from its roots. The celebration of a mixed-race, syncretic Brazil has been positive, but it has also had a heavy toll on many. This is because the valuation of a mixedrace Brazil has not come about as a clear response to the horrors that were perpetrated, which would involve public commitments to reverse the inequalities to which black people continued to be condemned even after abolition. It is true that miscegenation has defeated the hegemony of racism in a sense; however, it has done so by accentuating the contiguous line of the colonial past. Freirean theory, which it legitimised, mitigated the oppression of slavery, as if the justification of any positive reading of the miscegenation of races depended on establishing a bond with an underlying trend that was already, in its embryonic form, detectable at the heart of slavery. Miscegenation was the natural progression of Portuguese flexibility transplanted to the tropics. In other words, it would be a later stage of Brazilian historical evolution that would update aspects already present in the previous stages, giving them continuity over any negative, brutal and uncivilised elements. Brazilian wisdom would be able to dispose of negative components, and conserve power for the worthy.

Miscegenation would decant slavery, and thereby transcend it. This narrative does not account for the monster. It does not elaborate on the horror, or pronounce its name. Neither does it process - symbolically, emotionally or intellectually - the rupture that has happened culturally, if not politically. To name the horror, to recognise it, means marking a cut and a passage, means giving it meaning, circumscribing it and creating the conditions to overcome it, absorb it and battle it. The act of saying implies the act of doing, as the narratives in this case are also performative. We make things with words. The democracy of uniting the races until this nefarious concept becomes extinct is a beautiful ideal, but not if it happens through an origin myth that censures the horror, through the fairy-tale that racism does not exist in Brazil, or through the argument (which, while I realise it is well-intentioned, is in my opinion mistaken) that talking about it, denouncing it and applying policies to mitigate its effects are ways to involuntarily produce or strengthen it.

This ontological duality loses institutional rooting, and slips down an economic platform open to mediations that encourage the conversion of slave-property into an intensely exploited work force-commodity, 
in environments that lack economic, social, civil and political rights, and that are marked by the predominance of racist, authoritarian and hierarchical (whether patrimonial or class-led) cultural formations. One should remember that (limited) labour guarantees were applied only in the 1960s - and came at the same time as the political repression imposed by the dictatorship and by oligarchic violence.

Seen in this context, the great migration corresponded to a displacement of tectonic plates, deepening inequality and producing further traumatic experiences.

\section{The great migration}

From 1950, and particularly from the start of the period of accelerated industrialisation in the middle of the decade until the end of the 1970s, it is estimated that 35.4 million people migrated from rural areas of Brazil to the cities. In 1950 only 36.63 per cent of the Brazilian population lived in cities. By 1980 the morphological configuration of traditional Brazil was reversed: 70.32 per cent of the population was urban. In 2010 86.11 per cent of the Brazilian population lived in cities. In view of the size of the population and the speed of change, especially between 1950 and 1980, the phenomenon was extraordinary. It should also be noted that, at its peak, this process took place under the dictatorship. These migrants did not have any channels of expression of their own, any tools of organisation, nor could they count on any welfare state worthy of the name. They were launched into the urban jungle in their millions.

The effects were traumatic and the factors of migration, which were in general negative, showed that the attractions and opportunities offered by industrial modernisation were outweighed by the hardships encountered by workers, who found themselves subjected to ruthless exploitation. 'The forced displacement to the cities ... was, in the great majority of cases, experienced as a process of loss and decay', in the words of Moacir Palmeira and Afrânio Garcia, whose work in this area has been very important (Palmeira and Garcia, 2001: 65).

Without a doubt, it would be a mistake to generalise such varied emotions and personal and collective experiences: indignation at the poverty, humiliation and abuses; hopes for a better life; fear of the unknown; and worry. These were then followed by the stresses of arriving and the need to search for a place to live and work. In many cases, the original networks from the rural community were restructured in the city, at least 
partially. Those who arrived first and managed to settle themselves acted as the trailblazers, paving the way for family, friends and neighbours: they gave advice, shelter, guidance, mediation and help. Others arrived on the off chance, unprepared, sleeping anywhere, eating whatever they could find, taking any opportunity offered. Between these two oppositional narratives is a multitude of others. There was no single path or destination. There was a vast range of adaptive dynamics, depending on the context and individuals' ability to weave personal relationships or find occupations that would guarantee survival.

Despite these considerations about the errors of generalisation, it is reasonable to assume that there are some shared characteristics. Either at the same time or in stages, fathers, sons, mothers and entire families made the exodus from the countryside to the cities - which were not ready or willing to offer shelter, and the crystal broke into a thousand pieces. They ended up having to build shacks that were merely premature ruins. They aged prematurely, under the extreme pressure from such radical change. The effort to adapt is not simple. It would be wrong to think of the adaptive process by seeing the subject from the perspective of two different objects: the prior fully coded life, and then the urban life waiting to be mapped out; all that are needed are a cognitive process, and the simple exchange of a hoe for a cement wheelbarrow. If it were this simple, migration would be merely a combination of learning and willpower: all that migrants need to do is change their belief systems so that their new lives in the city will match new categories. This analytical way of thinking is incorrect. It misses out something essential - which is that, in addition to the brutality of the impoverishment of this process, the people who suffer the most radical impact are the subjects themselves. They are not the same in the two scenarios. It is true that the objects change, but the subjects are not static either. They literally lose their ground. It was not their knowledge that told them what their lives were before the exodus; it was their lives before the exodus that told them who they were. This previous life was composed of many ingredients: the community, family, work, the land, the landscape, belief systems, values, the temporality of rural life, and the rhythms and upsets of nature.

It is true that rural life is not always a harmonious community experience between peers, fellow workers and their families - not to mention the oppressive relations with those who are unequal, because these are ubiquitous. In the extreme and tragic case of drought driving away the people of the land, the social fabric becomes frayed. In the Brazilian 
reality, it is worth repeating that the routes to migration have been multiple. There are many migrants who have managed to overcome hardships and challenges and redefine their crossing over as liberation. Lula, Luiz Inácio Lula da Silva, was a migrant who became president and a national hero, and became an icon of affluence at all levels.

\section{The radicalism of change}

One can learn from Tim Ingold - and numerous Brazilian writers and poets - that human beings do not live in a single place. We cannot even say that we are part of a place, as we are, in part, the place itself. Admitting this is tantamount to acknowledging that migration on a wide scale corresponds to a displacement of the tectonic plates of Brazilian society. This event will continue to have long-lasting repercussions. To a certain extent, the men and women who migrated travelled far from themselves, distanced themselves from who they were, and perhaps even lost themselves. In the city, they threw themselves into the radical adventure of inventing a new subject, a new character for themselves, a person they could inhabit, someone who inhabited the city, a place entirely strange - the strangeness being intensified through involving both the relations of the subjects to themselves and the subjects' relations with their new social universe, new language and new way of life.

Tim Ingold is the anthropologist who has perhaps written most extensively and profoundly on this. In contrast to the Western supremacy of form over process, he posits the 'dwelling perspective' as opposed to the 'building perspective' (Ingold, 2000: 173). Reflecting on the Heideggerian idea that there is a significant difference between dwelling and living and between a house and a home, Ingold believes that there is much more in the experience of living than simple occupation. Living goes beyond the separation between public and private; it transcends the limits of a domestic home and extends its content to being in the world: 'thus "I dwell, you dwell" is identical to "I am, you are"' (Ingold, 2000: 185).

In addition to the category 'dwell', Ingold works with the concepts of landscape and temporality, distinguishing them from those of land and chronology: 'where land is thus quantitative and homogeneous, the landscape is qualitative and heterogeneous' (Ingold, 2000: 190). Landscape is not to be confused with the concepts of nature and space, and neither should temporality be diluted through calculable extension 
and isomorphically divisible units of physical time. Temporality is the social journey of human beings through the landscape, marking it with the dynamic experience of living through the cycle of life; dwelling is understood as being in the landscape, engaged in it through all kinds of activities and interactions, each of which corresponds to different paths. He teaches us that every map is encapsulated in a way of life (Ingold, 2000: 225).

Ingold shows that the analytical separation between a tradition and its territory, and between a culture and its place, means becoming distanced from the traditional knowledge of the context in which it was produced, and from the practical experience from which it emerged. This is experience situated in a specific and ecologically significant environment. The consequence of this artificial separation is to reduce a 'form of life' to a 'world view' or 'cognitive schema' (Ingold, 2000: 225). This intellectual movement is like the transposition of an organic immersion, from the phenomenological perspective, to the metaphysics of representation that operates through the dualism of subject-object. ${ }^{3}$

If one agrees with Ingold and applies his perspective to the great migration in Brazil, this presents new challenges. To reiterate, as perhaps now the argument has become clearer: this vast migration can be compared to a dislocation of the tectonic plates of Brazilian society. It was the subjects themselves who suffered the most radical impact of this transformation process, as they could not be the same in both settings. Objects change, settings change, and the subjects change too. They literally lose their ground. To reiterate: it was not their knowledge that told them what their lives were before the exodus; it was their lives before the exodus that told them who they were. The echo of ontological duality is reclassified but remains undiluted. On the contrary, if becomes more concentrated.

\section{Democratic transition detached from the masses}

There is another key point here: it was in this context that the transition to democracy was enshrined in the promulgation of the Federal Constitution in 1988. This coinciding of two such different temporalities, the great migration and the change of regime, may help to explain the distance between the civic enthusiasm of Ulysses Guimarães (a federal deputy, and then president of the Chamber of Deputies), holding up the new constitution, the new social contract - the sign of his triumph 
in the National Congress - and the indifference of the people, with an ingrained scepticism of a system that encouraged inequality and the continuation of societal injustice. On one hand there was the institutional language of the state, and on the other there were the still audible echoes of ancestral ontological dualism, the delayed eloquent vibrations of the unsaid and the persistence of historical traumatic repression.

More than three decades have passed since the democratic state of law was established. More than thirty years of advances, macro-economic stabilisation, poverty reduction, expansion of citizenship, cyclical electoral mandates - this is what one would have said before the huge crisis that has engulfed the country since 2015. And despite the advances (which are now being challenged if not revoked), relations between state and society are still marked by mistrust and tutelage; and, with the crisis, this is only increasing. The inequality of access to justice continues to resist change, and the mechanisms that reproduce the order still perpetuate the atavistic face of police brutality against blacks and the vulnerable poor. Unfairness, violence, environmental destruction and representational crisis coexist alongside more widely celebrated achievements. In this wave of inert reiterations, the trail of ontological dualism rips the surface of society like a scar resistant to change, avoiding the official maps.

\section{Synthetic conclusions}

The above leads one to the following hypotheses.

(1) The ontological duality initiated by four centuries of slavery, which has continued through the racism and injustice in the twentieth century and been repressed in the national memory, finds creative and reversive approaches when the cultural and social dynamics of the 'I-You' type erupt, radically transforming the process of circulating voices, lines of power and authority, and deposits and sources of value. For example, Tropicalism was (and has left us with) an experimental laboratory for a new 'I-You' individuality and dialogue.

(2) The dialogical scheme in the relationship with alterity cannot be consolidated without socio-economic transformations and radical policies, and without reducing inequalities and addressing structural racism in all its manifestations.

(3) Any acceptance in Brazilian society of a new model of relating to the Other involves, implies and presupposes the establishment of 
interventions (always multidimensional) aimed at building and maturing individuality, as subjective and inter-subjective experience, as a judicial-political category in the field of rights and as the source and target of values - the basic meaning of which is dignity. To this end, the combined yet unequal development of capitalism, even with its authoritarian nature, has paradoxically - or dialectically - contributed to and generated our conservative modernisation. This has happened because the paroxysmal progression of individualism, so desired by globalised market dynamics, generates a further contradiction by creating conditions in which individuals can go through the looking glass, radicalise their experiences and escape the commercial orbit that defines them as consumers and reduces them to mere calculations of utility and function. ${ }^{4}$ This liberating process requires an insidious and capillary revolution, one that has potential to reach a historic scale.

(4) Outside parties and institutions, and in the midst of so many tensions, individuality starts to grow in Brazilian society, an individuality that is constructed, lived, strengthened and expanded by social groups and individuals for whom the axis of accretion is on a plane that is invisible to anyone who sees only conjuncture or focuses on traditional sociological variables, which separate reality into layers. The strength of individuality and of the individuals and groups who embrace it creatively, in its multiple dimensions, cannot be identified or evaluated by sectoral analyses that look at human rights, values and subjectivities, and to a lesser extent, the market or the world of institutional interests and policies, even though all these areas are pertinent and relevant. There has been more space (even though any generalisation is of course overly simplistic and incorrect) to respect the individuals who dare to reinvent themselves from their own personal grammars, who rebel against labels and classifications, diagnostics and stigmas, fixed judgements and the determination of biographical fate, without cutting ties with their experience of empathy and solidarity, and recognising the same freeing potential in the Other. Meandering and highly individualised itineraries in religion, or in the field of spirituality, are just one example among many that bear witness to this trend. Experiments that distinguish body, sex, gender and identity also represent cutting-edge contributions that are of great importance for individuality. In the midst of intolerant reactions, and often with great difficulty, these inventors of themselves (in connection with collective agenda and repertories) have achieved remarkable successes in the country, broadening the territory of individuality as 
experience, and pointing to correspondent reconstruction whether in the sphere of category, of the law or of value, promoting the substitution of morality as a code for that of morality as openness to the Other and availability. Minority movements with connections to the defence of religious tolerance and liberty play a decisive role. Even though they are not strictly minorities, the feminist and anti-racist movements are stronger and better nourished by these virtuous dynamics, and this opens space in the midst of so many different barriers and forms of social, economic and cultural oppression.

(5) In addition, in parallel to the modest but significant reduction of poverty, for two decades the country has seen an increasing valuation of equality and the language of citizenship - running the risk, it is true, of the reductionist judicialisation that drains policies and invades privacy. However, going in the opposite direction of this democratising process is the counter-reformation, guided by a neo-liberal economic governance agenda in alliance with the most conservative moral supporters and skilled at articulating themselves with rhetoric, calling for tougher laws, longer sentences, more freedom for the arms trade, the war against drugs and the criminalisation of poverty, and more police violence. To crown this perverse agenda, they advocate policies that destroy the environment and annihilate the lands of the indigenous peoples. Under such an empire of hatred, the political culture is impoverished and retreats, blunting the imagination and dialogue, which ends up being fairly consistent with the role accorded to Brazil by the international division of labour. The country seems resigned to its agro-exporter fate, even in the twenty-first century.

One must conclude by admitting that, despite the fine words and the glimmer of other hopeful possibilities, the remains of this ontological duality are still among us, ripping at the heart of the country. Hatred has not ceased to circulate in the veins of the sleeping giant. It flows like a river of blood whose source has never ceased to be the masters' house.

And that is Rio de Janeiro.

\section{Notes}

1 Translations in this chapter were commissioned by the editors of the volume except where otherwise stated. 
2 Translated from the Portuguese translation of the original French source text.

3 It is interesting here to compare Ingold's position to the pragmatism of William James (2000) and Richard Rorty (1979), in whose works - other than specific differences - the disposal of the Cartesian pair does not give rise to a holistic concept, but rather to a dislocation of cogito to praxis, which brings Ingold back into the conversation.

4 For the analysis of a further seventeen contradictions, see David Harvey (2016).

\section{References}

Benveniste, É. (1966a). De la subjectivité dans le langage. In Benveniste, É., Problèmes de linguistique générale, 258-66. Paris: Gallimard.

Benveniste, É. (1966b). La nature des pronoms. In É. Benveniste, Problèmes de linguistique générale, 267-76. Paris: Gallimard.

Boiteux, L., Wiecko, E., Batista, V.O., and Prado, G. M. (2009). Tráfico e Constituição: Um estudo sobre a atuação da justiça criminal do Rio de Janeiro e de Brasília no crime de tráfico de drogas. Revista Jurídica, 11: 1-29.

Buck-Morss, S. (2009) Hegel, Haiti and universal history. Pittsburgh: University of Pittsburgh Press.

Gilroy, P. (1993). The Black Atlantic: Modernity and double consciousness. Cambridge, MA: Harvard University Press.

Harvey, D. (2016). 17 contradições e o fim do capitalismo. São Paulo: Boitempo.

Hegel, G.W.F. (1991). The elements of the philosophy of right, trans. H.B. Nisbet, ed. A. Wood. Cambridge: Cambridge University Press.

Hegel, G.W.F. (2018). The phenomenology of spirit, trans. M. Inwood. Oxford: Oxford University Press.

IBGE (Brazilian Institute of Geography and Statistics) (2010). Censo 2010, https:// censo2010.ibge.gov.br/en/noticias-censo.html (last accessed 1 November 2019).

Ingold, T. (2000). The perception of environment: Essays on livelihood, dwelling, and skill. London: Routledge. Kindle ed.

James, C.L.R. (1938). The black Jacobins: Toussaint l'Ouverture and the San Domingo Revolution. Harmondsworth: Penguin.

James, W. (2000). Pragmatism and other writings. New York: Penguin.

Palmeira, M., and Garcia, A. (2001). Transformação agrária. In I. Sachs, J. Wilheim and P.S. Pinheiro (eds), Brasil, um século de transformações, 38-77. São Paulo: Companhia das Letras.

Pinsky, J. (2010). Escravidão no Brasil. São Paulo: Editora Contexto. Kindle ed. Rorty, R. (1979). Philosophy and the mirror of nature. Princeton: Princeton University Press. 
Soares, L.E. (2016). Rio de Janeiro: Extreme city. London: Penguin.

Viveiros de Castro, E. (2008). A inconstância da alma selvagem. São Paulo: Cosac \& Naif.

Waiselfisz, J.J. (2011). Mapa da violência. Brasília: Ministério da Justiça. 